\title{
Extradigital glomus tumor: A case report
}

\author{
JI-SUN CHUN ${ }^{1}$, RAN HONG ${ }^{2}$ and JUNG-A KIM ${ }^{3}$ \\ Departments of ${ }^{1}$ Plastic Surgery and ${ }^{2}$ Pathology, College of Medicine, Chosun University; \\ ${ }^{3}$ Department of Complementary and Alternative Medicine, Chosun University Graduate School, \\ Gwanju 501-759, Republic of Korea
}

Received August 9, 2013; Accepted November 4, 2013

DOI: $10.3892 / \mathrm{mco} .2013 .219$

\begin{abstract}
A glomus tumor is a benign vascular tumor derived from the modified smooth muscle cells of the glomus body. The lesions develop as small blue-red nodules that are usually located in the deep dermis or subcutis of the upper or lower extremity. The single most common site is the subungual region of the finger, but other common sites include the palm, wrist, forearm and foot. In the present study, we report the case of a 45-year-old patient diagnosed with extradigital glomus tumor of subcutaneous tissue of elbow. Histopathological examination revealed that the tumor was a well-circumscribed nodule with focal invagination of tumor cells into the adjacent upper dermis. The tumor was composed of solid sheets of cells interrupted by vessels of varying size. Immunohistochemically, the tumor cells were reactive for smooth muscle actin (SMA) and vimentin (VMT). The majority of glomus tumors may be treated adequately by the correct diagnosis and simple excision. However, extradigital glomus tumors are occasionally difficult to diagnose owing to their non-specific clinical characteristics, including unusual sites and symptoms which vary compared with those of classical glomus tumors. Therefore, it is crucial to include glomus tumors in a differential diagnosis of patients with extradigital lesions.
\end{abstract}

\section{Introduction}

Glomus tumors constitutes $1.6 \%$ of all soft tissue tumors and are distinctive neoplasms that resemble the Sucquet-Hoyer canal of the normal glomus body, located in the subcutaneous tissue, which is responsible for the regulation of temperature and blood pressure (1-3). These tumors are usually solitary, deep blue to purple in color, and accompanied by the classic triad of pain, cold sensitivity and point tenderness (2). The glomus tumor was originally considered to be a form of angiosarcoma until the findings demonstrated by Masson (4)

Correspondence to: Professor Ran Hong, Department of Pathology, College of Medicine, Chosun University, 375 Seosukdong, Donggu, Gwangju 501-759, Republic of Korea

E-mail:nanih@chosun.ac.kr

Key words: glomus tumor, elbow in 1924 (3). Masson compared the tumors with the normal glomus body and suggested that the lesion represented hyperplasia or overgrowth of this structure (3). The most common site for these tumors is the distal extremities, particularly in the subungual digital areas, although tumors have been identified in extradigital sites including the bone, tongue, stomach, rectum, mesentery, lung, mediastinum, sacrum, coccyx, and the head and neck $(5,6)$. In the present study, we report a case of extradigital glomus tumor of elbow.

\section{Case report}

A 45-year-old male patient presented at Chosun University Hospital (Chosun, China) with a painful nodular lesion of the elbow. The patient presumed this lesion to be a puncture wound caused by pricking his elbow on a tree two weeks previously. Local examination revealed a violet-colored, mobile nodule. Mass excision was performed following a clinical diagnosis of hemangioma. Histopathologically, the surgical specimen indicated a subcutaneous, well-circumscribed nodule with focal infiltration into the upper dermis in the subcutaneous region (Fig. 1B). The tumor was $0.9 \times 0.7 \mathrm{~cm}$ and was comprised of sheets and a nest of uniform and round cells, interrupted by vessels of varying size (Fig. 1A). Certain areas had an organoid or epitheliod growth pattern. High-power examination with a light microscope at x200 magnification (BX51, Olympus, Tokyo, Japan) revealed that the glomus tumor cells exhibited punched-out and hyperchromatic nuclei and pale cytoplasm (Fig. 1C). A dense fibrous pseudocapsule surrounded the solid sheet of tumor cells. The tumor cells were immunoreactive for smooth muscle actin (SMA) (Fig. 1D) and vimentin (VMT). The final pathologic diagnosis was that of a glomus, solid-type tumor.

\section{Discussion}

The presence of glomus tumors in sites other than the hand makes an early and accurate diagnosis difficult. However, following the correct diagnosis, the treatment involves complete surgical excision (7). Diagnosis of a glomus tumor is primarily clinical as imaging techniques, such as plain radiography, magnetic resonance imaging, ultrasonography and angiography, do not yield a specific image of the tumor as they may only show the precise location and size of the tumor (8). 
A

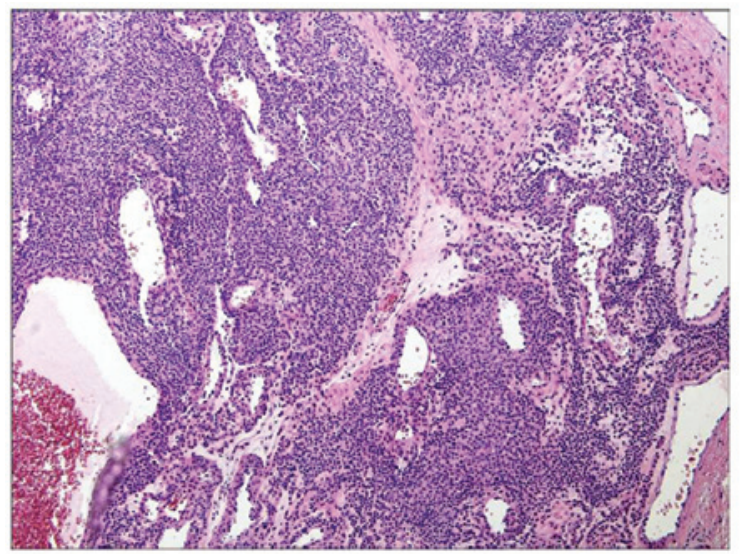

C

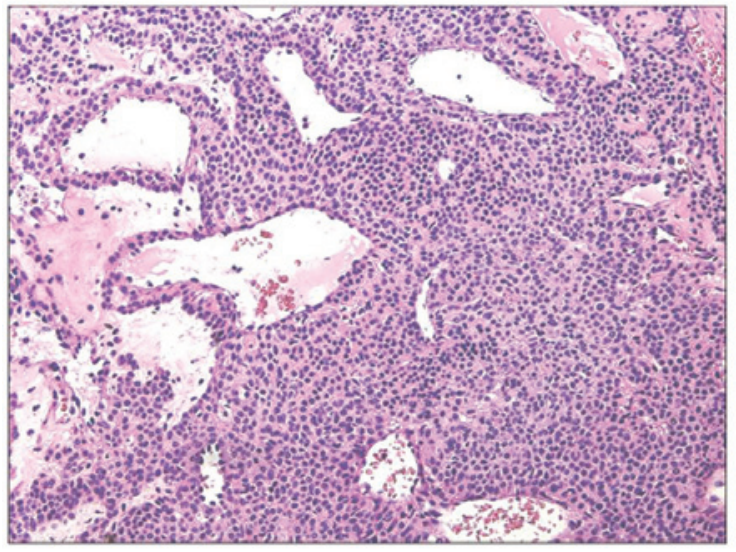

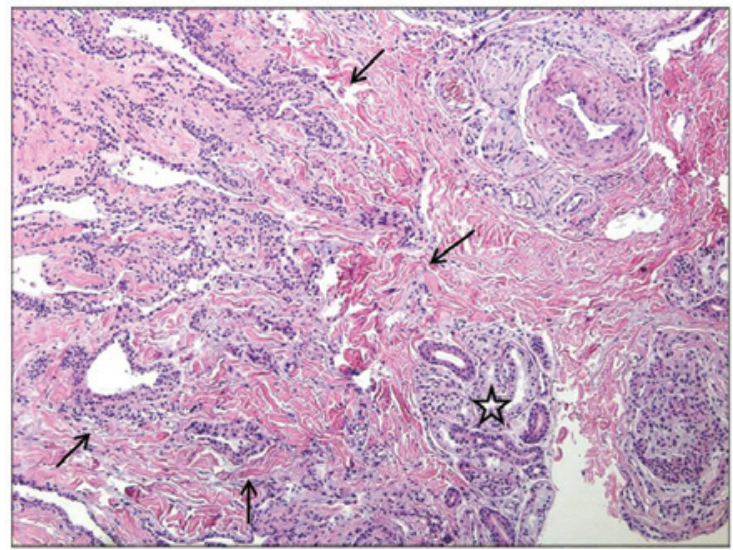

D

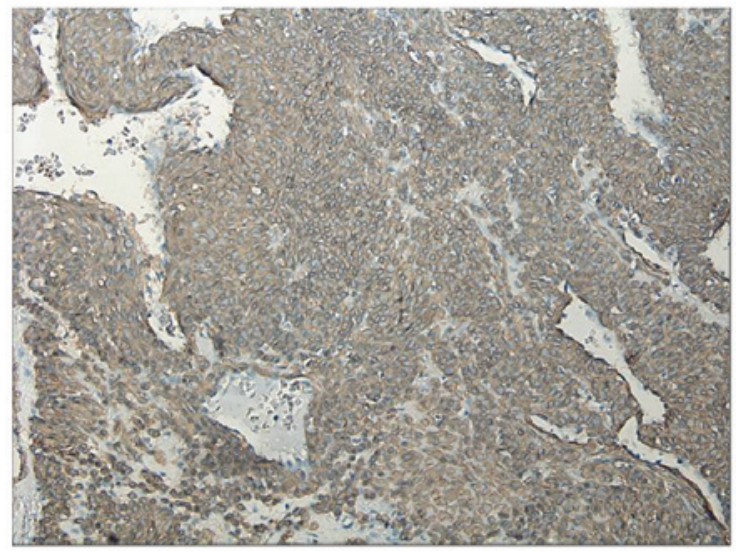

Figure 1. Histopathological findings. (A) The tumor comprised sheets and nest of uniform and round cells, interrupted by vessels of varying size. Focally, the tumor cells invaded the adjacent skin adnexae (H\&E staining; magnification, $\mathrm{x} 100)$. (B) The arrow reveals the tumor component and the star is adjacent to the eccrine duct (H\&E staining; magnification, x100). (C) High-power examination revealed that the glomus tumor cells exhibited punched-out and hyperchromatic nuclei and pale cytoplasm (H\&E staining; magnification, x200). (D) The tumor cells were immunoreactive for smooth muscle actin (SMA).

Beaton et al (9) suggested that the frequency of extradigital cases varied from 11 to $65 \%$ and may be more common in males than females. Lee et al demonstrated that extradigital glomus tumors are more common in males, whereas digital tumors are more frequent in females (2). The most prominent sites of extradigital glomus tumors have been reported to be the hands, followed by the feet and forearms (10). Other atypical locations where glomus tumors occurred and were excised include the lower lip (11), mediastinum (12), shoulder (13) and upper back (13). Folpe et al (14) examined 52 atypical glomus tumors located on thigh, calf and ankle, foot, buttock, trunk and abdomen, arm, lung, stomach and L3 vertebra.

Symptoms of glomus tumors are typical and often out of proportion to the size of the neoplasm. Paroxysms of pain radiating away from the lesion are the most common complaint (3). These epidoses may be elicited by changes in temperature, particularly by exposure to the cold, and tactile stimulation even to a minor degree (3). The mechanism of pain production requires further elucidation, however, identification of nerve fibers containing immunoreactive substance $\mathrm{P}(\mathrm{SP})$ in glomus tumors suggests pain mediation through the release of this substance (3). SP is a pain-related peptide that acts as the main afferent pain transmitter in glomus tumors $(15,16)$. McKemy suggested that thermosensitive afferents express ion channels of the transient receptor potential (TRP) family, which respond at distinct temperature thresholds, thus establishing a molecular basis for thermosensation (17). TRPV1 is a capsaicin receptor that acts through the release of SP. Furthermore, SP and TRPV1 correlate closely, although the exact association remains unclear (2).

Accurate diagnosis followed by complete excision is regarded as curative for patients with solitary lesions, and recurrence rates for solitary tumors have been found to range from 12 to $33 \%(18,19)$. It is rare for malignant glomus tumors to occur. Refined criteria have been suggested to define malignant lesions (14), including deep location and a size of $>2 \mathrm{~cm}$, or atypical mitotic figures, or moderate to high nuclear grade and $\geq 5$ mitotic figures per 50 high-power field (14). Lesions with marked nuclear atypia but no other malignant features are termed symplastic. Glomus tumors of uncertain malignant potential are defined as lesions that lack criteria for the diagnosis of malignant or symptomatic glomus tumors but have high mitotic activity and superficial location, large size only or deep location only (14).

In conclusion, we reported the case of an extradigital glomus tumor arising in the subcutaneous tissue of the elbow. Unusual tumor sites and differing clinical symptoms occasionally interfere with the diagnosis and treatment of patients with extradigital tumors. Therefore, it is important to include the glomus tumor in the differential diagnosis of patients with extradigital painful or asymptomatic lesions that are purple in color. 


\section{References}

1. Rathi KR, Jena J, Dash BM, Mitra D, Patnaik PK and Basu AR: Extradigital glomus tumor as a cause of chronic perianal pain. Indian J Pathol Microbiol 52: 414-416, 2009.

2. Lee DW, Yang JH, Chang S, Won CH, Lee MW, Choi JH and Moon KC: Clinical and pathological characteristics of extradigital and digital glomus tumors: a retrospective comparative study. J Eur Acad Dermatol Venereol 25: 1392-1397, 2011.

3. Weiss SW and Goldblum JR (ed.): Perivascular tumors. In Enzinger and Weiss's Soft tissue tumors. 5th edition. Mosby, Maryland Heights, MO, pp751-756, 2007.

4. Masson P: Le glomus neuromyoarterial des regions tactile et ses tumors. Lyon Chir 21: 257, 1924.

5. Kale SS, Rao VK and Bentz ML: Glomus tumor of the index finger. J Craniofac Surg 17: 801-804, 2006.

6. Enzinger FM and Weiss SW (ed.): Perivascular tumors. In: Enzinger and Weiss's Soft tissue tumors. 4th edition. Mosby, Maryland Heights, MO, pp985-1035, 2001.

7. Tomak Y, Dabak N and Ozcan H: Extradigital glomus tumor of the triceps tendon as a cause of elbow pain: a case report. J Shoulder Elbow Surg 12: 401-402, 2003.

8. González-Llanos F, López-Barea F, Isla A, Fernández-Prieto A, Zubillaga A and Alvarez F: Periosteal glomus tumor of the femur; a case report. Clin Orthop Relat Res 380: 199-203, 2000.

9. Beaton LI and Davis L: Glomus tumor: report of three cases and analysis of 271 recorded cases. Q Bull Northwest Univ Med School 15: 245-273, 1941.

10. Calonje E: Vascular tumors: tumors and tumor-like conditions of blood vessels and lymphatics. In Lever's Histopathology of the Skin. 10th edition. Lippincott Williams and Wilkins, Philadelphia, PA, pp1047-1049, 2009.
11. Lanza A, Moscariello A, Villani R, and Colella G: Glomus tumor of the lower lip. A case report. Minerva Stomatol 54: 687-690, 2005.

12. Gaertner EM, Steinberg DM, Huber M, Hayashi T, Tsuda N, Askin FB, et al: Pulmonary and mediastinal glomus tumors - Report of five cases including a pulmonary glomangiosarcoma: a clinicopathologic study with literature review. Am J Surg Pathol 24: 1105-1114, 2000

13. Takei TR and Nalebuff EA: Extradigital glomus tumour. J Hand Surg Br 20: 409-412, 1995.

14. Folpe AL, Fanburg-Smith JC, Miettinen M and Weiss SW: Atypical and malignant glomus tumors: analysis of 52 cases, with a proposal for the reclassification of glomus tumors. Am J Surg Pathol 25: 1-12, 2001.

15. Kishimoto S, Nagatani H, Miyashita A and Kobayashi K: Immunohistochemical demonstration of substance P-containing nerve fibres in glomus tumors. Br J Dermatol 113: 213-218, 1985.

16. Wu JS, Huang ZJ, Zhou JF, Lin M, Fang MR, Pang ZJ, and Yan HD: Expression and significance of substance P, neurofilament-H in glomus tumors with chronic pain. Zhonghua Wai Ke Za Zhi 41: 935-939, 2003 (In Chinese).

17. McKemy DD: How cold is it? TRPM8 and TRPA1 in the molecular logic of cold sensation. Mole Pain 1: 16, 2005.

18. Rettig AC and Strickland JW: Glomus tumor of the digits. J Hand Surg Am 2: 261-5, 1977

19. Strahan J and Bailie HW: Glomus tumour. A review of 15 clinical cases. Br J Surg 59: 91-3, 1972. 